\title{
Why deflationary nominalists shouldn't be agnostics
}

\author{
Jody Azzouni
}

Published online: 3 June 2014

(C) The Author(s) 2014. This article is published with open access at Springerlink.com

\begin{abstract}
A feature of agnostic views-views that officially express ignorance about the existence of something (God, mathematical abstracta, theoretical entities) - is that they are widely perceived to be epistemically more cautious than views that are committed to (or against) the entities in question. This is often seen as giving agnostics a debating advantage: all things being equal, fence-sitters have smaller argumentative burdens. Otávio Bueno argues in this way for what he calls "agnostic nominalism," the view that we don't know whether ontologically-independent Platonic objects exist. I show that agnostic nominalism, so called, can be sustained only in ways that don't give agnostic nominalists debating advantages: the position must either be deduced from antecedently-held broader sceptical assumptions or it requires manufacturing potential referents for one's terms that artificially generate grounds for scepticism. Neither maneuver leads to an agnostic nominalism with a debating advantage over its nominalist opponents.
\end{abstract}

Keywords Agnostic nominalism - Deflationary nominalism - Scepticism - The epistemic role puzzle $\cdot$ Bueno $\cdot$ Quine-Putnam indispensability thesis

\section{First Preliminary: three motivations (and two argument-strategies) for nominalism}

Nominalists deny Platonic objects exist. And, depending on the nominalist, the list of nonexistent Platonic objects can be quite large: pure and applied mathematical objects of most sorts: numbers, points, topological neighborhoods; universals, properties and relations; possible worlds, possible entities; types; species; words,

\footnotetext{
J. Azzouni $(\bowtie)$

Tufts University, Medford, MA, USA

e-mail: jodyazzouni@mindspring.com
} 
sentences, meanings. As alarmed establishment philosophers will notice: pretty much every toy that philosophers like to play with is on this list.

Motivations for nominalism range from the superficial invocation of "fundamental intuitions" (Goodman and Quine 1947, p. 174) to various forms of intellectual irritation at the metaphysical queerness of purported Platonic objects (e.g., acauality, weird or nonexistent identity conditions) to epistemic worries (e.g., the Benacerraf 1973 puzzle in the generalized form of the absence of reliability conditions on the knowledge of these things).

One subsidiary aim of this paper is to offer another argument for nominalismone that's based on language use.

\section{Second Preliminary: characterizing agnostic nominalism}

Bueno (2008, 2009) calls himself an "agnostic nominalist." ${ }^{1}$ My Webster's New World Dictionary describes agnosticism as "the doctrine of agnostics: distinguished from atheism." The noun "agnostic," in turn, applies to "a person who believes that the human mind cannot know whether there is a God or an ultimate cause, or anything beyond material phenomena." ${ }^{2}$ Although philosophers almost always tamper with the words they co-opt from the vernacular, this isn't very far from Bueno's use of the word. He tells us that agnostic nominalists believe that (2008, p. 101) "perhaps mathematical objects exist, perhaps they don't," because (2008, p. 100) "it's not clear how we could establish the non-existence of mathematical objects-particularly without begging the question against the Platonist" (italics his).

Bueno (2008, p. 100) distinguishes agnostic nominalism from "the negative, skeptical claim to the effect that mathematical objects do not exist." Bueno misuses "sceptical": a sceptical stance is understood to be an attitude, directed towards a body of purported knowledge, that we don't know what's taken to be known in that subject area. To be one or another kind of sceptic is to proclaim that we don't know if there is an external world, or to proclaim that we don't know if there is life on other planets, or to proclaim that we don't know if there is a God. Sometimes the sceptical position is extended to the statement of the very sceptical position itself: we don't know if we don't know what the (dogmatic) sceptic thinks we don't know.

Traditional agnosticism, therefore, is a sceptical position, and Bueno clearly also means his agnostic nominalism to similarly be a (local) scepticism, despite his denying the appropriateness of that label. It's true that, during chitchat, one understates disbelief in something by saying, "I'm kind of sceptical about that"; but

\footnotetext{
${ }^{1}$ More accurately, Bueno (2009) has waffled on terminology: he's also described the position as "agnostic fictionalism." Because of a tension between "agnostic" and the words "fictionalism" and "nominalism," neither label is optimal. Better labels would use the adjective "Platonic," or "mathematical," as in "Platonic agnosticism," or "mathematical agnosticism." I'll continue to use "agnostic nominalism" and its cognates in this paper, however, because Bueno's agnosticism favors nominalism over Platonism in important respects that I want readers to stay aware of.

2 We're also told that the word was coined by Thomas Huxley in 1870.
} 
this involves the irony that always accompanies understatement. "Doubt" is similar. I can say "I doubt that," and mean I don't believe in its possibility-even a little bit. I can also use "doubt" to express a genuinely sceptical state of mind: I don't know what to think.

What, however, is the word "nominalism" doing here? We all know how contemporary philosophers use "nominalism": it's one of a family of positions that denies the existence of Platonic objects. How does one both deny the existence of such objects and yet proclaim that one doesn't know one way or the other? Bueno's reason for using "nominalism" is that, apart from the epistemic stance of noncommitment, he takes the appropriate analysis of the methodology of the mathematical sciences as operating within the confines of nominalism-that is, without the presupposition of the existence of mathematical objects. Bueno (2008, p. 101) writes:

The central point of agnostic nominalism is that we need not take mathematical objects to exist in order to make sense of mathematical practice. Perhaps mathematical objects exist, perhaps they don't. Nothing in mathematical practice seems to require the existence of these entities. ${ }^{3}$

The last sentence is crucial. At no stage in the analysis of mathematical practice, does a requirement for independent mathematical entities arise. ${ }^{4}$ It's Bueno's allegiance to this methodological strategy that he clearly means to signal by labeling himself an "agnostic nominalist." The agnostic nominalist avoids invoking mathematical objects when characterizing mathematical practice-when explaining what mathematicians are doing, and why mathematics is so useful in empirical applications. On the other hand, he dons the trappings of epistemic virtue (in contrast to the belligerent nominalist) by denying that these object-free ways of understanding mathematical practice can be used against their existence. He simply says (about whether mathematical objects exist or not): well, I wouldn't know about that.

Two points just made will be crucial later. First: agnostic nominalism is a kind of scepticism. This allows the possibility of deducing agnostic nominalism from broader sceptical assumptions; and this matters because we must be clear when agnostic nominalism is being supported by considerations independent of broader sceptical assumptions and when it isn't. Second, the agnostic nominalist is nominalistic about characterizing mathematical practice. I'll say still more about this in the next section and in Sect. 4-but notice now that the agnostic nominalist

\footnotetext{
${ }^{3}$ I argued for a similar position in Azzouni (1994, 2000); see the discussion of the epistemic role puzzle in Sect. 3. My motives for being agnostic about Platonic objects during that time, however, had to do with a distrust of Quine's criterion coupled with a concern that a replacement criterion (either for discourse or for what exists) wasn't available-this isn't what's motivating Bueno (2008, 2009). As I indicate: his concerns seem to be about burden shifting.

4 This is a powerful assumption, as I discuss in later sections. In particular, Bueno rejects Quine's criterion. Therefore: when it comes to the truth and falsity of mathematical statements, or the quantifier expressions and noun phrases of mathematical language, no presupposition of mathematical entities is taken as required. It's here that Bueno's agnostic nominalist aligns with the deflationary nominalist, as I indicate in Sect. 4. The issue, of course, is whether doing this is compatible with agnosticism.
} 
can't borrow explanatory resources from Platonism. To say, "nothing in mathematical practice seems to require the existence of these entities," as Bueno does, is to say that everything in mathematical practice can be explained without presupposing mathematical entities. It's this assumption of the agnostic nominalist that's used against the position later.

\section{The epistemic role puzzle}

One thing that enables the agnostic nominalist to claim that we needn't take mathematical objects to exist in order to make sense of mathematical practice are the insights provided by the epistemic role puzzle, ${ }^{5}$ a puzzle arising from the observation that mathematical objects play no epistemic role in mathematical practice. A philosopher might try to argue that this observation is actually a sceptical challenge; ${ }^{6}$ but it's not. It's a quotidian comparison between ordinary mathematical practice and epistemic practices in the empirical sciences. When studying perception, for example, we examine the causal relations between the seeing organism (its eyes and brain) and the objects seen. That the cow's eye is insensitive to colors the human eye is sensitive to makes cows far more susceptible to contrast effects than humans are. To understand this, we use facts about the objects seen and the mechanisms by which they are seen. Scepticism about the external world, therefore, must not only undercut the existence of external objects, it must simultaneously undercut perceptual mechanisms. Otherwise, in a sceptical thought experiment in which objects in a room vanish, our already-in-place description of how perception works will require that the people in the room see that they've vanished.

Similar constraints cannot be found in the epistemology of mathematical practice. Were mathematical objects to suddenly vanish, mathematicians would continue as before. (No aspect of mathematical practice would change due to these objects no longer existing.) Despite this, some philosophers of mathematics still take intuition seriously. If they presume such intuitions are of mathematical objects, they can't rely on there being mechanisms, like the senses, that are already recognized as ways of learning about the external world, and that are already recognized as studied by science. Proponents of intuition of mathematical objects must postulate the existence of object-tracking mechanisms on the basis of perceptual analogies, or treat the perceptual aspects of mathematical practice (e.g., use of diagrams and written proofs) as part of an inference-process to mathematical objects and their properties, as for example, in Katz (1998).

Even if a philosopher describes (some) mathematical objects as in space and time, and therefore as perceivable (e.g., Maddy 1990), the position is still threatened by the epistemic role puzzle: perception of mathematical objects-however the

\footnotetext{
5 See Azzouni (1994, Sect. 7). McEvoy (2012) has recently argued that the epistemic role puzzle reduces to Benacerraf's (1973) puzzle. I respond to this argument in Azzouni (forthcoming).

${ }^{6}$ See McEvoy (2012, pp. 300-303).
} 
philosopher metaphysically reconstrues them-has no role in mathematical practice. It's no response to make up a metaphysical story that puts mathematical objects in space and time, and according to which (therefore) perception of them occurs, unless one also convinces mathematicians to change their practices so that at least some of their results depend on the perception of mathematical objects as the philosopher requires.

Another way to recognize the scope and power of the epistemic role puzzle is to note that accompanying any description of genuine perceptual mechanisms (by which we recognize some of the properties of some objects) is a description of artifacts-perceptual mistakes - that those mechanisms induce. More broadly put, an important part of any characterization of perceptual mechanisms is that such a characterization explains (and even enables us to predict) ways in which aspects of the perceptual mechanisms mislead its users into false descriptions of objects and their properties. Inferential tools, in particular, provide one way that we can be misled (by missteps in inference). Optical illusions (of various sorts), in the sensory case, provide distinct ways to be misled. It's striking that our perceptual grasp of the external world exhibits (in various degrees) both forms of mistake. Optical illusions - in particular - are robust effects (e.g., the Müller-Lyer illusion, Sander's parallelogram, and Tolansky's curvature illusion $)^{7}$ that aren't a class of inferences precisely because our (inferred) knowledge that, e.g., the lines have the same length, that the curvatures are the same, doesn't affect what we see.

There is nothing is like this in mathematical practice. One can be misled by aspects of a proof procedure-this is regardless whether formal proofs, informal proofs, diagrams, or even empirical methods (e.g., computers) are used. No noninferential access to the properties of mathematical objects, however, occurs in mathematics. This is indicated both by the absence of a distinctive study of artifacts of such purported noninferential methods, and (more directly) by the absence of any empirical study of such methods themselves.

"Nothing in mathematical practice seems to require the existence of these entities"- - one thing this means is that the epistemic practices of mathematics don't invite this requirement.

When a proponent of agnostic nominalism discusses "intuition," therefore, he instead characterizes intuition's role to exclude the relevance of objects. Bueno (2008, p. 103) writes: "mathematical facts are not understood as facts about existing mathematical objects, but as facts about what follows from certain principles and relations among concepts (which are, of course, not understood as abstract entities)." Intuitions (2008, p. 104) are "about fruitful way(s) of introducing mathematical definitions-one(s) that seem to lead to more interesting, powerful results." And, "by exploring the intuition of these concepts, mathematicians can determine which among various definitions seem to be the most fruitful ...."

Intuition, on the agnostic nominalist's view, is demoted from perception of independent mathematical objects to a facility with psychological concepts and various principles, including comprehension principles; intuitions are explained

\footnotetext{
7 Illustrations of these are everywhere on the web.
} 
entirely by aspects of mathematical proof and aspects of the psychology of the mathematician who makes or understands proofs.

An important observation: The agnostic nominalist doesn't think that perhaps independent mathematical entities are involved (somehow) in mathematics, or perhaps they're not. The agnostic nominalist isn't agnostic about this: such entities - whether they exist or not—are definitely not involved. Putting the matter another way: the agnostic nominalist's dayjob, when engaged in explaining what mathematicians do (and how they do it) is identical to the nominalist's dayjob. Both deny a role to mathematical objects when describing how mathematicians come to know what they know. It's only in the evening - after the agnostic nominalist kicks back (with a drink in his hand) — that he says with a sigh: Do mathematical objects exist? Who knows?

\section{Distinguishing deflationary nominalism from reconstructive nominalism}

I turn now to the other important way that agnostic nominalists think "nothing in mathematical practice seems to require the existence of these entities." This is that agnostic nominalists think that nothing about the semantics of mathematical languages requires independent Platonic objects.

To make the agnostic nominalist's semantic presuppositions clear, a distinction between deflationary and reconstructive nominalism is needed (see Bueno 2013). The reconstructive nominalist links truth to ontology. One way is by some version of correspondence truth; another is by Quine's criterion for ontological commitment. Either way, denying a sort of Platonic object leads inexorably to the requirement of avoiding the truth of statements with noun phrases that refer to (or quantifier expressions that range over) those objects. The deflationary nominalist rejects Quine's criterion and correspondence truth. The deflationary nominalist, thus, uses Platonic language freely; reference to and quantification over Platonic objects don't commit her to the existence of them (see Azzouni 2004b, 2010a).

This isn't the end of the matter-philosophically speaking. Rejecting Quine's criterion and correspondence truth only "levels the playing field" against Platonism. Especially in the late twentieth century (when the strategy finally became explicit), Quine's criterion and correspondence truth were Platonic tools that forced Platonism on anyone who believed that certain truths were indispensable. Rejecting this package allows an ontologically-neutral construal of truths that have terms that purportedly refer to (and range over) Platonic objects-but that alone doesn't mandate nominalism.

Some nominalistically-inclined philosophers may invoke —at this juncture-an a priori methodological principle, such as Occam's razor. The proponent of this distasteful maneuver has overlooked that we can't a priori dictate the ontology of the universe (see Azzouni 2000).

Epistemically-modest philosophers (agnostics) see an opportunity here. Because the debate about Platonism-especially about the Quine-Putnam indispensability thesis - is focused on pushing the burden of argument against the nominalist or Platonist, the possibility of agnostic non-commitment has been overlooked (except, 
as far as I know, by Otávio Bueno). The appropriate epistemic attitude, says the agnostic (deflationary) nominalist, is to accept the neutral construal of noun phrases and quantifier expressions that, respectively, refer to and range over Platonic objects. But a neutral construal of noun phrases and quantifier expressions doesn't dictate a positive ontological attitude. Maybe these things exist; maybe they don't. Who knows?

Consider three possible argument-strategies against Platonism: the epistemic, the metaphysical, and the linguistic. I'll take up the linguistic argument-strategy starting in Sect. 5, but here's something brief about the other two approaches now. Epistemic objections to Platonism seem to fit comfortably with agnosticism. Consider the worry, for example, that our epistemic practices don't reliably dictate that our claims about Platonic objects correspond to the properties those objects actually have (e.g., Field 1989). This doesn't—all by itself_-invite denying Platonic objects. If successful, this only undercuts what we think we know about these objects; it doesn't undercut our being right by sheer accident-these objects could exist even though we haven't any reasons for thinking they do.

Metaphysical objections are different. They achieve an incoherence charge against Platonic objects if they're successful. The most well-known example is Quine's poor-individuation-conditions-complaint-one he directs against possible objects, Meinongian beings, meanings, and so on. Philosophers have responded in the intervening decades by nicely cleaning up individuation conditions for these objects. A different metaphysical objection is to press a criterion for what existse.g., causal efficacy-against Platonism. If this criterion can be motivated independently of debates between nominalists and Platonists, it can be nonquestion beggingly brought against Platonists and for nominalists. But (see Azzouni 2010b), I've argued that no such criterion can be philosophically motivated because our ordinary concept of ontology_of what really exists-has no such criterion built into it.

Still left standing is the strategy of motivating a metaphysical criterion on grounds we take seriously: ontological independence (mind and language independence) is the candidate I've urged. We take seriously — so I claim (Azzouni 2012) the line between those objects (and their properties) that we discover those objects to have independently of us, and those objects (and their properties) that are instead either stipulated by us (individually or collectively) or that, more generally, are psychological or sociological projections. The claim is that this distinction-if sustained-is one we take very seriously; that makes it a good (although not definitive) candidate for the line between the real and the unreal. This is so even if nothing in our notion of the genuinely real allows us to prove that the genuinely real is coextensive with the ontologically-independent.

It's unclear, however, that this criterion for what exists helps the nominalist against agnosticism. Platonic objects, after all, are supposed to be ontologicallyindependent in the designated sense. Nevertheless, two points should be stressed again about the agnostic nominalist's claim that "nothing in mathematical practice seems to require the existence of these entities." (1) There is an adherence to the epistemic role puzzle (described in Sect. 3): mathematical objects play no epistemic role in mathematics. (2) There is also an adherence to a deflationary view of the 
semantics of quantifier expressions and singular terms in mathematical discourse: mathematical objects need play no semantic role in mathematical practice.

\section{Correspondence and non-correspondence uses of language: some illustrations}

I've discussed (briefly) the epistemic and the metaphysical argument strategies for nominalism and against Platonism; I've suggested they either don't work or don't favor the nominalist over the agnostic. I turn now to meeting my obligation to provide a new argument-strategy-one from language use. The plot of the next few sections is this. I first distinguish two roles for noun phrases and quantifier expressions: the correspondence role and the non-correspondence role. I next give some toy illustrations of the non-correspondence role, ones where participants are aware of that role. In Sect. 6, I turn to cases where people are mistaken about what roles their noun phrases and quantifier expressions have. It will also be shown that agnosticism isn't an appropriate attitude when noun phrases and quantifier expressions are used non-correspondingly. In Sect. 7, the epistemic role puzzle will be used to establish that the non-correspondence role is at work in mathematical practice. In turn, that the agnostic nominalist accepts the insights of the epistemic role puzzle will be used against his agnosticism.

Noun phrases (and quantifier expressions) have two distinguishable roles in natural languages. A purportedly central and widely-recognized role is the naming of things - and more generally, the talking about things - that we're antecedently trying to study and interact with. ${ }^{8}$ Call this the "correspondence role." The correspondence role is apparently exhibited not only towards various species of object we perceive and interact with in our daily lives, but also (and more esoterically) towards theoretically-posited entities of science: the microphysical paraphernalia of physics, visually-inaccessible macro-objects, and so on. Some theologically-posited entities of the various revealed religions should be included here as well.

Because we humans are so clever, there is a quite different role in natural language for noun phrases and quantifier expressions: I'll describe this as the "noncorrespondence role."

A first illustration of the non-correspondence role: If we ask (in a grammar class) about the direct object of the sentence "John sent Mary a book," the right answer will be "a book" (Anscombe 1965, p. 6). But this isn't to say that there are particular people, John, Mary, and a particular object-a book-that are being spoken of. It would be odd to think this-doing so misunderstands the use of these sentences in this context. Given the description of the language situation, it's equally odd to be agnostic: maybe there are such people (and a specific book). Maybe not. Who can ever be sure about this?

\footnotetext{
${ }^{8}$ Recognition of this role for names occurs early. See Genesis 2:20. Similar acknowledgements of this role for names can be found in most other religious-mythic traditions.
} 
It's not, of course, impossible to take a sceptical (agnostic) stance in this context (as the italics three sentences back indicate). That's not the point; the point is that one can acquire agnosticism only in certain ways. If you recognize you are in a classroom studying grammar, then it isn't possible for you to have an agnostic attitude about whether the sentence "John sent Mary the book," is about particular people and a book. To be agnostic about this, you have to think that you might be mistaken about what's happening. It's not really a classroom. Or the class discussion isn't really about grammar. Or it's both these things, but the teacher is a spy sending a message to one of the students (another spy) about actual people and objects: "John," "Mary," and "the book." Given, however, that the situation is as it appears (grammar is being innocently studied in a classroom), agnosticism about the references of "John" and "Mary" isn't possible.

If you ask who Mary and John are, people who are appraised of the situation will think you don't understand what's going on; people, similarly appraised, take agnosticism to indicate a similar failure. This is empirical evidence, that apart from peculiar wrinkles, "Mary," and "John," so used, are playing a non-correspondence role in these kinds of cases.

A second illustration: Imagine a game where the goal is to exhibit (during rounds, and according to specific rules) sentences with so many "e"s "o"s or "t"s. I write "John sent Mary a book," and win the round. It would be as daft to say that "John" and "Mary" refer to people in the sentence I've written down as it would be to say that we should be agnostic about whether they refer to particular people or not. We're playing a game. As before, agnosticism isn't-in principle-ruled out: perhaps we're not playing a game (perhaps it only looks that way) ....

A third illustration: Two small children "pretend up" their entire subject-matter: they make up characters that they talk about. They "make up" or stipulatealthough small children, of course, wouldn't use that word-what's true and false about who they're talking about. They imitate all the verbal practices they've acquired for talking about real objects-they use "know," "true" and "false," for example, in ways indistinguishable from how they use these idioms with respect to real objects. In particular, they "argue over" what's true or false about the objects they're discussing; they complain they don't know certain things about their characters (because it's a "secret"). This game doesn't need physical props (e.g., dolls or toys) and the children don't even need to borrow characters from the various media they're familiar with.

The natural way to construe what these children are doing is to say that their terms don't involve language-world correspondences. Correspondingly, it doesn't make sense to adopt an agnostic stance towards the referents of their terms; it doesn't make sense-if we know what kind of game they are playing - to say that we nevertheless don't know whether or not the objects exist that the children are talking about.

Some-but not all-adult storytelling is similar. We're adults, let's say, and we're bored to death because we've unwisely agreed to sit around a campfire in some forest or other. (Even worse, we've foolishly agreed to be out of range of the internet which everyone here, naturally, is addicted to.) Someone tries to break up the tedium by saying: "Once upon a time, there was a couple, John and Mary. They 
owned a book of witchcraft ...." A story is now being told. We recognize that "John" and "Mary" don't refer to anyone, although we're all engaged in the mutual pretence that these names refer.

It would be confused-a misunderstanding of how these sentences are being used-to adopt agnosticism this way: well, yes, I understand this, but still, even with a pretence being engaged in, "John" and "Mary" might actually refer to people (somewhere or other). No. Words don't refer by accident and against our explicit intentions. If names are introduced into a context where they are deliberately being used not to refer, it makes no sense to accept that description, but then claim that-nevertheless-one doesn't know whether these names do refer.

In every case I've given, I stress again, agnosticism hasn't been ruled out. Rather, agnosticism has to be introduced in the right way. Perhaps the campfire storyteller reveals - at the end of her narrative - that her story was true, that Mary and John are friends of hers. We thought we were engaging in a pretence (because the storyteller seemed officially to be telling a fiction) but we've now learned she tricked us, and wasn't engaged in pretence at all. An agnostic stance in these cases requires, that is, an antecedent scepticism about the situation.

The campfire-story case is instructively simple. Storytelling conventions, first, give the storyteller the right to determine the referential facts. The story can be pure pretence, if the storyteller means it that way. The storyteller, instead, can intend that certain terms aren't pretence, but refer. For example, she might tell a story to inform her students about the solar system: it's understood that everything she says about the solar system is true, although the aliens Fe and Cre, who are writing a travel guide to the universe, don't exist.

Within the story (within the pretence), second, all the standard devices of ordinary language-usage can occur. That is, within the story, there can be repeated tokens of names that are taken to pretendedly co-refer. The word "true" can also be used: Everything Mary told John was true, but he didn't believe her. The word "refer" can appear, because the story can itself be about (in part) a story that's not supposed to be true or to refer to anyone (in the story): "Once upon a time 'unicorn' referred to real creatures, but 'troll' didn't. Jack, the mad biogeneticist, intended to change that fact ...."

There is another important way that agnosticism can be introduced-by what I'll call "theory-mediation." A philosopher can argue that noun phrases and quantifier expressions used during story telling are necessarily correspondence uses. Here's a philosophical position: there are mind- and language-independent entities that terms in stories actually refer to (whether or not people want this) — abstracta for example. Some philosophers (e.g., van Inwagen 2000) have argued for this by making claims about how quantifiers and singular terms work-that such idioms require ontology to function semantically. This philosophical view allows the following agnostic position into logical space: I don't know whether arguments like van Inwagen's are successful or not. Therefore: I'm agnostic whether storytellers, children or otherwise, refer to mind- and language-independent entities. I'm similarly agnostic whether trolls, fairies, and so on, exist or not.

"Theory-mediated agnosticism" is similar to an agnosticism that challenges our knowledge of the set-up of the language situation. The difference is that language- 
situation agnostics doubt whether people really are telling stories, or whether children really are children. Theory-mediated agnostics instead have doubts about how our language works - in particular, they have doubts about whether reference to mind- and language-independent entities must occur whenever we use noun phrases and quantifier expressions.

Because the agnostic nominalist, as we saw in Sect. 4, accepts the ontologicallyneutral role of the quantifiers (so that he isn't agnostic about how quantifier expressions and noun phrases semantically work), he can't adopt theory-mediated agnosticism except by broader sceptical grounds (e.g., I don't know for sure any philosophical claims I make). Nevertheless, he can still attempt agnosticism about whether these expressions are correspondence-used or non-correspondence-used in the context of mathematics. I now turn to ruling out this option. The first step is to extend the illustrations of non-correspondence uses of language to cases where speaker-hearers are mistaken about these uses.

\section{Being mistaken about the roles of one's inherited terms}

It's an empirical question where and when non-correspondence uses of language occur. I've argued in earlier work (Azzouni 2004b, 2010a) that they occur surprisingly often - that they are so common that instead of taking the correspondence role of language as fundamental (as nearly every philosopher does), it would be-perhaps-more accurate to our history, and current practices in the sciences and elsewhere, to instead treat the non-correspondence use of language as fundamental.

One thing that has allowed human beings to so extensively non-correspondently use language is that speaker-intentions needn't determine whether quantifier expressions and noun phrases are functioning correspondingly or non-correspondingly.

Imagine a community where everyone believes in hobbits, elves, and fairies. A deference practice — a linguistic division of labor (Putnam 1975, pp. 227-229)—for these noun phrases is in place. Just as we rely on experts to tell us when we definitively have gold, rubies, and various chemicals, people in this community rely on experts to tell them when there's been a genuine hobbit-sighting, or when someone's home is infested by fairies. Suppose these experts belong to a specially trained coterie - their knowledge isn't shared with the community at large. You join this coterie, and you're trained for years in the specialized lore of hobbits, elves, and fairies. You reach the pinnacle of the hierarchy (you're introduced into the inner sanctum) and you learn the truth: hobbits, fairies, and elves don't exist. The purported existence of these beings are only necessary myths for certain (political) purposes. You've learned that what most people believe in, and believe that you're an expert in, doesn't exist. This is an empirical discovery about your own language (as well as about fairies, elves and hobbits).

Other ways of discovering that the noun phrases (that you think refer) don't: you trace back a practice of deferred reference, and find that it originates in a myth that subsequent speakers take to be a real story about existing participants, or in a conspiracy to fool everyone about someone's existence, a conspiracy that succeeded 
(until you exposed it). Furthermore, imagine the deferred reference doesn't involve subsequent reference-fixing events. ${ }^{9}$ What's attributed to this person either didn't happen, or happened to several different people who otherwise share nothing in common. The reference (or nonreference) of noun phrases, therefore, can be ontically deferred; the same is true of what quantifier expressions range over.

The preceding examples are narrowly illustrative: they don't indicate the many ways that we can mistake the role of the noun phrases and quantifier expressions in a language practice we've inherited. One reason for this potential error is that noun phrases and quantifier expressions aren't semantically marked with an ontological status; subsequent speakers can easily misconstrue them. Thus: what role these expressions play is an often difficult empirical question turning on facts about our language history and current usage.

Here is an example where a referential misconstrual was driven by philosophical mistakes. I've claimed (Azzouni 2004a) that the diagrammatic items, points, lines, etc. (of Book II of Euclid) were misconstrued as referring Platonic objects by ancient Greeks. I argue that what drove this conclusion were philosophical mistakes about the truth idiom; it was thought that for geometric sentences to be true their terms had to refer, and that those terms couldn't refer to parts of drawings. Coupled to this was an additional mistake: that a body of doctrine, like Euclidean geometry, can't be empirically valuable if it's false.

My purpose here isn't to argue for these claims about Euclidean geometry-I've done that already. My purpose is to indicate a possibility: if this was how a belief in Platonic objects arose, then that would be relevant historical evidence that contemporary mathematical terms are used non-correspondingly despite Platonists continuing to think otherwise. ${ }^{10}$

\section{Undermining Platonism and agnostic nominalism with considerations from language use}

Here's where we're at. The agnostic nominalist wants to be agnostic about whether mathematical terms are employed correspondingly or not. My counterstrategy, in the next two sections, is to show that "nothing in mathematical practice seems to require the existence of these entities" rules out an agnosticism that shifts the burden of argument against the deflationary nominalist. Let's see how this goes.

An important assumption in play is that a deduction of agnostic nominalism from a background scepticism doesn't successfully shift the argumentative burden. The

\footnotetext{
9 So this isn't like Evans's (1973) Madagascar case where, although the original reference-fixing is to a different landmass than what the word is subsequently taken to refer to, there are also subsequentlyreinforced usages to the subsequently referred-to landmass.

10 Additional supplementary argument-both historical and contemporary-is needed to extend this claim to other mathematical terms, and is also needed to show that the referential practices of Euclidean geometry haven't changed in the intervening centuries. But if right, this line of argument is fatal to agnostic nominalism. Although Bueno has not (to my knowledge) weighed in on this particular historical claim, I assume he thinks it's wrong. In any case, I'm leaving further exploration of this aside because the agnostic faces problems in any case, as I illustrate in the rest of this paper.
} 
debate between nominalists and agnostic nominalists isn't supposed to turn on background sceptical assumptions. The generalization of the Benacerraf (1973) puzzle to worries about reliability constraints on knowledge about Platonic objects, for example, is supposed to be a specific charge that can be brought against Platonic objects but not against other sorts of objects. Revealing it as instead only a more general sceptical argument undercuts its force against Platonism. ${ }^{11}$ Call this The it isn't scepticism assumption (for short: "The Assumption”).

Let's return to the third illustration (in Sect. 5) about two children who stipulate imaginary beings that they talk about. To say, about those children (or worse, to those children), that they might have-by accident—succeeded in referring to (and speaking truly about) a set of objects in some inaccessible part of the universe, or in another possible world (or whatever), is to have missed the point of the childrens' "language game" - to borrow Wittgensteinian language.

The terms of their language, I want to say, are referentially empty. Some philosophers, however, are convinced that ontologically-dependent constructed objects arise from the childrens' mutual thought-game, that these things exist, and are the referential targets of the terms the children use. Thomasson (1999) has such a view. Such objects are "ontologically dependent," in the sense that their properties are products of the children's thought-game, rather than these objects (and their properties) being independent of the children's thought-game. ${ }^{12}$

This is relevant to a complication in Bueno's position (2009, especially Sect. 3.3.1) that I've repressed mention of until now. He doesn't agnostically regard mathematical terms as (possibly) referentially empty, but instead (explicitly mentioning Thomasson's views), he takes the relata of mathematical terms (and what the quantifiers in mathematical languages range over) to definitively refer to various constructed objects that emerge into existence because of mathematical work.

The nominalistic agnosticism that Bueno officially endorses, therefore, isn't about the objects that mathematical terms refer to-he takes those terms to refer to "constructed" objects that exist. Bueno (2009, p. 71) is agnostic about Platonic objects, which are described as existing independently "of any description [in mathematical terms]."

Why should we be agnostic about Platonic entities the way Bueno is, when (on his view) our very own mathematical terms don't refer to them? The Assumption allows us to disregard global epistemic modesty assumptions, that we can never be sure about any ontological assumption. Are there specific reasons to be agnostic about mind- and language-independent Platonic objects? I turn to considering two kinds of agnostic nominalism, given the wrinkle in Bueno's position that I just described. The first is one on which mathematical

\footnotetext{
11 See, e.g., Katz (1998) and Burgess and Rosen (1997), for versions of this charge directed against Benacerraf's (1973) puzzle.

12 I think there are no such "constructed" objects, that our community-wide criterion for what existsmind- and language-independence-rules them out. I indicated this view briefly at the end of Sect. 5. See, e.g., Azzouni (2004a, b, 2012). Whether I'm right or wrong about this doesn't affect the debate between nominalists and agnostics.
} 
terms do refer to constructed objects (one is agnostic not about reference, but about Platonic objects of such and such types). The second is one on which the agnostic nominalist is agnostic about the references of mathematical terms. I argue that neither agnostic nominalist has an argumentative advantage over the (deflationary) nominalist.

\section{Two languages}

Let's start by getting more precise about Bueno's agonistic position. This agnostic nominalist claims that he's in no position to know whether there are objects (or not) that exist and that have certain properties, objects that are abstracta (for example), that are ordered as numbers are, or that have the properties that mathematicians attribute to functions, and so on. I put the point this way because Bueno is agnostic about ontologically-independent objects that have (some of) the properties we attribute to the ontologically-dependent constructed objects that our mathematical terms actually refer to.

Compare the case to this one. Suppose we agree that "orc" doesn't refer; or suppose we think "orc" refers to fleeting constructed objects ontologically dependent on our story-making. We can still be agnostic about the possibility of ontologically-independent orcs. We can say:

I don't know whether ontologically-independent orcs exist or not. I don't know whether sentient beings that originally were men but were subsequently bred into evil creatures by someone like Sauron, as he appears in The Lord of the Rings, and so on, exist or not.

Because our word "orc" doesn't refer (or it refers to ontologically-dependent things), to make this speech consistent, we introduce a new word "orc"," impound the definitions in play for storybook "orcs," and express our agnosticism as about orcs $^{\#}$ (rather than as about orcs).

An immediate worry about this strategy is its presupposition that the words in question- "Sherlock Holmes," "orc," and so on-are words that have (even in pretence) definitions. Although this is a working assumption of paraphrase strategists with respect to negative existentials (e.g., they replace "Zeus doesn't exist," with "There is no unique king of the ancient Greek gods who threw thunderbolts from the sky"), it's not obvious that such words do operate by implicit definitions of this sort; there are good reasons to think otherwise. ${ }^{13}$

This problem doesn't seem to arise for mathematical noun phrases because mathematics is replete with definitions. Let's grant this. The metaphysical objects that this version of agnostic nominalist is agnostic about can, therefore, be characterized by a blend of description, some of the content of which replicates axioms from mathematics proper, and some of which is compatible with that practice but has been introduced by philosophers. The Platonist claims the existence

\footnotetext{
$\overline{13}$ See Azzouni (2010a, Chap. 3), for arguments that fictional names are singular.
} 
of (and the agnostic nominalist denies knowledge of) objects that are: not in space and time, not acausal, and that are linearly ordered according to definitions that mimic the axioms of Peano Arithmetic. Characterizations of other purported abstracta are similar.

Bueno stresses that these objects-ones that he's agnostic about-have nothing to do with mathematics or with mathematical practice. Strictly speaking, therefore, his agnosticism isn't directed towards mathematical practice or the language deployed in that practice. His reasons for agnosticism, instead, must turn on general claims about his inability to know, one way or another, what kind of funny furniture there might be in the universe; these reasons for agnosticism can have nothing specific to do with what he says about mathematical practice. His agnosticism seems based, that is, on his denying that he can ever know whether negative existentials are true. "Agnostic nominalism," as a description for his position, has broken in two. The nominalism is focused on mathematical practice; the agnosticism is omnidirected towards negative existentials of all sorts.

Perhaps there are acausal objects not in space and time, the agnostic nominalist thinks. How would we ever know? Perhaps some of these acausal objects that aren't in space and time have the properties attributed to numbers. Call them $0^{\#}, 1^{\#}, 2^{\#}, \ldots$, etc. Some of these objects could have the properties attributed to geometric objects. Call these objects points", lines", etc. How can we possibly ever know whether these objects exist or not?

I stress again that these worries have nothing to do with philosophical issues about mathematical practice or about mathematical language. With the same justification for agnosticism, one can say this: perhaps there are universes causally isolated from ours that aren't in our space and time. (Perhaps there are other spaceand-times ${ }^{\#}$, how would we ever know?) And in those universes, perhaps, there are orcs $^{\#}$, hobbits", and gremlins". How would we ever know? These worries aren't about our myths and fairy tales. We know that "orc," "hobbit," and so on, as we currently use these words aren't meant to refer (or are meant to refer to ontologically-dependent objects). But that's not true of the words "orc"," "hobbit"," or "gremlin"."

Some philosophers think they don't have a right to use the word "know" in a fashion that allows them to claim that they know (on the basis of current knowledge) that such-and-such things don' $t$ exist. To prove this, some of these philosophers coin new words (ones not already in our language), and use these words to successfully refer to certain things (if they exist); and they then argue that we don't know whether these certain things exist or not. They place the burden of argument on their opponents of having to justify claims to know that these things don' $t$ exist.

It's an old story in epistemology that resolving where the burden of proof lies in debates like this isn't easy. The sceptic makes up a description of something or other, and immunizes it against empirical tests for its existence by characterizing it, say, as outside space and time, as acausal, and so on. Then she forces her opponent into scepticism by demanding he provide an argument for his knowledge claim that these things don't exist. He protests that the demand is unfair because her 
immunization process has undercut the tools standardly used to adjudicate-at least in principle-such knowledge claims one way or the other. ${ }^{14}$

It seems that the agnostic nominalist has been revealed to be this familiar oldfashioned sceptic of the kind epistemologists have been grappling with for ages; and that we have here the old burden-shifting-of-proof logjam that's already quite familiar to those epistemologists. It's important—as I've noted — that the agnostic nominalist not be an old-fashioned sceptic. Because he's an agnostic nominalist, he officially thinks he does know the things he claims to know about mathematical practice.

One indication that by employing this maneuver the agnostic nominalist has deduced his position from a more-generalized scepticism is that the strategy endangers knowledge claims he thinks he has. The agnostic nominalist thinks, for example, that abstracta play no role in mathematical practice. But he doesn't know this about abstracta ${ }^{\#}$. For abstracta ${ }^{\#}$, despite being acausal objects not in space and time, might nevertheless have powers ${ }^{\#}$ that enable them to play undetectable roles in our knowledge-gathering practices in the mathematical sciences by (say) influencing how we formulate axioms ....

Yet another objection can be brought against the agnostic nominalist who has adopted this strategy - and perhaps it can also be made to work more broadly against certain forms of general scepticism as well. ${ }^{15}$ This version of the agnostic nominalist has been revealed to be using words that aren't in our language. He is offering the traditional poisoned pawn (of chess): he's inviting us to speak a new language that contains referentially-apt noun phrases that imitate (some of) the ways of our own non-referentially-apt noun phrases. But it's built into the way the agnostic nominalist expands the language that scepticism must result. Recall the first illustration of Sect. 5, and consider "John gave Mary the book," when utilized in grammar classes. Imagine we introduce into our language words "John" and "Mary"," and stipulate that these words are to be taken to be referentially-apt, but their references, if any, are to be governed only by how these words are used in the grammar classroom. Scepticism about whether "John\#" and "Mary\#" exist necessarily results because there is nothing about how these words are used in the grammar classroom that indicates what, if anything, they could refer to. Similarly, if nothing in mathematical practice corresponds to conditions that could be used to indicate what mathematical noun phrases refer to, is it any wonder that importing words stipulated to be reference-apt, but which in addition are only to be fixed in their reference by mathematical practice, yields the result that we can't know whether these (new) words refer or not?

\footnotetext{
${ }^{14}$ Compare this to a scepticism about turtles. "There are no turtles on Mars," I say, "this is something I know." (I suspect this is something most people_-who know anything at all about Mars and turtlesthink that they know.) "No," my opponent responds, "what about those turtles that don't need water, that are invisible to all our methods of tracking them, that can live on Mars, that are genetically distinct from turtles on Earth, and so on?" I respond that there aren' $t$ any turtles like that. But perhaps I'm begging the question against the sceptic. I respond that the word "turtle" doesn't mean anything like that. It's not obvious, however, that I have a right to say this either.
}

15 This is an issue I can't explore further in this paper. 


\section{Does the debate between the agnostic nominalist and the nominalist end in a draw?}

Perhaps Bueno's commitment to constructed objects unnecessarily complicates life for agnostic nominalists. Let the agnostic nominalist instead simply agree that -at the current moment-there is nothing in mathematical practice or in mathematical language that determines what mathematical noun phrases refer to or that quantifier expressions in mathematics range over. This seems plausible-given the epistemic role puzzle, anyway, and the ontologically-neutral construal of the semantics of quantifier expressions and singular terms, both of which the agnostic nominalist accepts.

The agnostic nominalist can argue, however, that it's therefore indeterminate whether mathematical terms are being used correspondingly or non-correspondingly, and that the epistemic role puzzle and the ontological neutrality of the expressions of mathematics show this.

This isn't a burden-shifting maneuver against the deflationary nominalist, strictly speaking. The result, rather, is a draw; but the grounds of the draw, at least, aren't due to broader background sceptical assumptions or because of an artificial extension of the language we speak. Nevertheless, the maneuver doesn't work because indeterminacy about the correspondence role should count against the agnostic.

The reason is this. Once we accept, as the agnostic nominalist does, the ontological neutrality — semantically speaking - of singular terms and quantifier expressions, then these terms aren't going to function correspondingly unless they' re made to do this by a population using these expressions. Taking our terms to refer to what we perceive is one way to do this; deliberately using descriptions to enable our terms to reach into the world is another way. Yet a third is inertially acquiescing in a practice that earlier practitioners used to talk about items in the world. Regardless: the correspondence role can't happen by accident. And it's here that the epistemic role puzzle does serious damage to agnosticism. What enables the epistemic role puzzle to be posed in the mathematical context (and not in the context of empirical science, for example) is precisely that users of mathematical language aren't doing anything to enable their terms to reach out into the world.

Well, okay. Here's a last (somewhat artificial) maneuver open to agnostic nominalists. Suppose we engage in a non-correspondence language practice, or we recognize that a language practice-mathematical practice, say-that's already in place is non-corresponding. We can now stipulate the following condition for the terms of this language:

If a descriptions governing a term $t$ in the language fits something $b$, then then $t$ refers to $b$.

Given this stipulation, an agnosticism easily follows. After all, especially in the mathematical case, it seems easy to say: how do we know whether weird Platonic objects exist or not? 
Alas, this is another version of the strategy criticized in Sect. 8. Precisely because of the role in language certain terms previously had, our modification generates scepticism.

\section{Conclusion}

At least on the argumentative surface of things, it seems a genuine agnosticism about Platonic objects should be relatively easy to establish—one that turns on the details of the debate between nominalists and Platonists, and that isn't due either to a generalized background scepticism about negative existentials, or to a stipulation of the terms of the language that artificially induces a scepticism. And it seems that exactly such a position has been offered by Otávio Bueno. But upon probing, this has been found not to be: the agnosticism in question either depends on one or another form of general scepticism or involves reformulations of non-correspondence language that's otherwise not meant to refer.

Otávio Bueno may not be worried about this_at least, a version of him may not be worried. For versions of Bueno have often expressed sympathy with what I've described as "global scepticism." Otávio Bueno-or a version of him, anywaymay happily concede that agnostic nominalism can't stand on its own but must be derived from a more general scepticism. Nevertheless, it's an important result that this is true-especially for those of us who remain unsympathetic to global scepticism.

A second related point should be stressed about this. The strategy of undermining agnostic nominalism that I've offered in this paper is very language-specific: the strategy turns on exposing the properties of the noun-phrases and quantifierexpressions of a language-practice - in this case the language of (pure and applied) mathematics. Each case of language use is special, and the success or failure of an agnostic stance about a subject area turns on the nature of apparently-referential language in that case. ${ }^{16}$ Consider, for example, constructive empiricists, who would like to be agnostic about "unobservable entities." To employ the strategy of this paper, they need to show that the noun phrases and quantifier expressions in scientific-language practices have non-correspondence roles. It may seem possible for the tools I employ here to be used successfully by them. I think not, as I indicated in the last section; but this is a debate to be carried out in other work.

Acknowledgements My thanks to an anonymous referee for pressing me to explicitly discuss the issues in these last two paragraphs. My thanks to Otávio Bueno for many helpful suggestions on an earlier version of this paper. He remains completely unconvinced.

\footnotetext{
16 Notice my deliberate use of the weasel-word "case." It can be, of course, that the use of certain nouns and quantifier-expressions in one context are referential and in another context aren't. Indeed, a shift in "context" so understood can even happen in the course of uttering a single sentence. See Azzouni (2010a, b).
} 
Open Access This article is distributed under the terms of the Creative Commons Attribution License which permits any use, distribution, and reproduction in any medium, provided the original author(s) and the source are credited.

\section{References}

Anscombe, G. E. M. (1965). The intentionality of sensation: A grammatical feature. In The collected philosophical papers of G.E.M. Anscombe, Volume II: Metaphysics and the philosophy of mind (pp. 3-20). Minneapolis, MN: University of Minnesota Press (1981).

Azzouni, J. (1994). Metaphysical myths, mathematical practice: The ontology and epistemology of the exact sciences. Cambridge, MA: Cambridge University Press.

Azzouni, J. (2000). Stipulation, logic, and ontological independence. Philosophia Mathematica (3), 8, 225-243.

Azzouni, J. (2004a). Proof and ontology in mathematics. In T. H. Kjeldsen, S. A. Pedersen, \& L. M. Sonne-Hansen (Eds.), New trends in the history and philosophy of mathematics (pp. 117-133). Odense: University Press of Southern Denmark.

Azzouni, J. (2004b). Deflating existential consequence: A case for nominalism. Oxford: Oxford University Press.

Azzouni, J. (2010a). Talking about nothing: Numbers, hallucinations and fictions. Oxford: Oxford University Press.

Azzouni, J. (2010b). Ontology and the word "exist": Uneasy relations. Philosophia Mathematica (3), 18, 74-101.

Azzouni, J. (2012). Taking the easy road out of Dodge. Mind, 121-483(October), 951-965.

Azzouni, J. (Forthcoming). McEvoy on Benacerraf's problem and the epistemic role puzzle. In F. Pataut (Ed.), New perspectives on the philosophy of Paul Benacerraf: Truth, objects, infinity. New York: Springer.

Benacerraf, P. (1973). Mathematical truth. In P. Benacerraf \& H. Putnam (Eds.), The philosophy of mathematics (pp. 403-420). Cambridge, MA: Cambridge University Press.

Bueno, O. (2008). Nominalism and mathematical intuition. In G. Pryer \& G. Peter (Eds.), Philosophy of mathematics: Set theory, measuring theories and nominalism. Frankfurt: Ontos Verlag.

Bueno, O. (2009). Mathematical fictionalism. In O. Bueno \& Ø. Linnebo (Eds.), New waves in philosophy of mathematics (pp. 59-79). London: Palgrave Macmillan.

Bueno, O. (2013). Nominalism in the philosophy of mathematics. In E. N. Zalta (Ed.) Stanford encyclopedia of philosophy. Stanford, CA: CSLI Publications. http://plato.stanford.edu/.

Burgess, J. P., \& Rosen, G. (1997). A subject with no object. Oxford: Oxford University Press.

Evans, G. (1973). The causal theory of names. In Collected papers (1985) (pp. 1-24).Oxford: Oxford University Press.

Field, H. (1989). Realism, mathematics and modality. Oxford: Basil Blackwell.

Goodman, N., \& Quine, W. V. O. (1947). In N. Goodman (Ed.), Problems and projects (1972) (pp. 173-198). New York: The Bobbs-Merrill Company, Inc.

Katz, J. J. (1998). Realistic rationalism. Cambridge, MA: Bradford MIT.

Maddy, P. (1990). Realism in mathematics. Oxford: Oxford University Press.

McEvoy, M. (2012). Platonism and the 'Epistemic role puzzle'. Philosophia Mathematica (3), 20, 289-304.

Putnam, H. (1975). The meaning of 'meaning'. In Mind, language and reality: Philosophical papers (Vol. 2, pp. 139-152). Cambridge, MA: Cambridge University Press.

Thomasson, A. (1999). Fiction and metaphysics. Cambridge, MA: Cambridge University Press.

van Inwagen, P. (2000). Quantification and fictional discourse. In A. Everett \& T. Hofweber (Eds.), Empty names, fiction and the puzzles of nonexistence (pp. 235-247). Stanford, CA: CSLI Publications. 